\title{
Poor Prognosis Metastatic Gestational Trophoblastic Tumor
}

National Cancer Institute

\section{Source}

National Cancer Institute. Poor Prognosis Metastatic Gestational Trophoblastic Tumor.

NCl Thesaurus. Code C9178.

Metastatic gestational trophoblastic tumor in which risk factors are present. 